\title{
Methodological complexity in the study of consciousness
}

\author{
K. Zobenko \\ Department of Philosophy and Methodology of knowledge Mechnikova I.I. National University (Odessa, Ukraine) \\ Corresponding author. Email: zobenko.kseniya106@gmail.com \\ Paper received 05.05.18; Accepted for publication 13.05.18.
}

\section{https://doi.org/10.31174/SEND-PP2018-170VI70-15}

\begin{abstract}
Why are we conscious? How can it be that information processed in the human brain is accompanied by subjective experience? An integral part of the problem of consciousness is the methodology of its solution. A lot of different methods in the study of consciousness, the author define as a convergence of the basic properties of consciousness in connection with the change in the methodological characteristics of research programs. Methodological pluralism, characteristic for modern philosophy of consciousness, is manifested, first of all, as a set of research strategies for solving the problem of consciousness and their interpretations.
\end{abstract}

Keywords: consciousness, methodology, pluralism, philosophical attitude, reflection, approaches.

Introduction. The study of human cognition has always been one of the main tasks of philosophy. In conditions of the development of experimental and mathematical science in science, a steady practice of applying natural-science research methods to traditional objects of philosophy is fixed; here I single out consciousness as a way of knowing the world by man. In the era of modernity there is an intensive differentiation of sciences, in the conditions of which the specificity of cognition and human consciousness are studied not only in the field of humanities, social sciences, philosophy, but also in the field of technical and computer disciplines: neurophysiology, neuroinformatics, and artificial intelligence. Achievements of the XX-XXI centuries in the conditions of scientific and technological progress had a colossal influence on the present, whereby the modern world is overflowed with artificial objects (artifacts), which have practically replaced natural objects. Technological transformations uniquely provoke social changes in society. Modern man is in the reality of the digital environment.

Paradoxically, and thus the complexity of this reality lies in the questions: 1. the digital environment simply belongs to the present, while being only one of its dimensions? 2. Or does the digital environment determine the life of a modern person? For natural objects it is characteristic that the process of their reproduction and functioning is completely independent of human existence and human activity, but the existence and functioning of artificial objects directly depends on this. And as applied to the problem of consciousness, one can observe tendencies of the convergence of the "natural" and "artificial" in understanding its nature. Modern technologies overcome the binary ontology of "natural" and "artificial". The study of the nature of consciousness in the modern world has become unthinkable without analogies with artifacts, virtualistics, and problems of artificial intelligence. At the present time, there has already been accumulated a sufficient array of experimental data on consciousness that require philosophical comprehension and they, in turn, influence the direction of research into the philosophy of consciousness. At the same time, in the process of philosophical comprehension of natural scientific data on consciousness, a methodological complexity arises that requires reflection. Empirical data obtained in the field of the natural sciences are not a homogeneous array of data, and this is a problem in the methodology of studying consciousness.

A brief overview of publications on the topic. Many philosophers dealt with the study of the specifics of the methodology of studying consciousness. For example, David Chalmers named the problem of understanding subjective experience the "hard problem" (Chalmers 1995, 1996). Us- ing Thomas Nagel's famous example, even if we had a complete knowledge of bat brains, we would never understand what it is like for the bat to have a sonar sense (Nagel 1974). The author also singles out an article P. Feyerabend "Realism. Rationalism and Scientific Method" (Feyerabend, 1999).

Materials and methods. In the course of the research, I used the principles, methods and techniques of the analysis of phenomena developed in modern philosophy and natural sciences. In particular, the epistemological principles of holism and complementarity played an important role in the study of the problem of consciousness, which allowed us to regard consciousness as a specific object of investigation.

Purpose. The purpose of this article is to reveal the essence of the methodological problems of investigating consciousness in connection with the change in the methodological characteristics of research programs.

Results and its discussion. Modern philosophy of consciousness supports the existence of various approaches as an important factor in the development of science. P. Feyerabend said that the existence of a set of equal types of knowledge contributes to the growth of knowledge and the development of the individual, and the most fruitful periods in the development of science are the periods of the struggle of alternatives, the origins of which are contained in the difference of the world outlook and social positions of scientists. [4; 83] Not less value for the development of science is represented by alternative theories, since in the process of their interaction and critical analysis, not only differences of theories are revealed, but also their similarity.

The value of philosophical innovations in the field of philosophy of consciousness is commensurate with that critical assessment of the current state of science. P. Merkulov draws attention to the fact that "at the disposal of researchers was a huge array of information on the functioning of the human cognitive system, which is incomparable in its scope and reliability with the knowledge that has been accumulated by mankind during the past millennia." $[2 ; 36]$ Now there are fundamentally new experimental methods for studying the brain, thanks to the development of the digital environment. For example, neurobiology is working on a brain-computer interface (BCI), which greatly simplifies communication with devices for those who have certain physical characteristics. Also, significant changes have occurred in the philosophical methodology of the study of the human cognitive system. Such a combination of circumstances and causes explains the trend in the development of philosophical thought, in particular, an increased interest in the problem of consciousness. This is evidenced by many research strategies 
for solving the problem of consciousness and their interpretations.

In the conditions of methodological pluralism, the question of which philosophical approach is most effective and expedient is relevant. There are no single-valued criteria for optimality of the chosen strategy. Multiple, but one-sided approaches do not give the desired result. [3; 268-274]

In this situation, alternatives are possible:

1. Consideration of philosophical knowledge about consciousness from the standpoint of the principle of complementarity, then different interpretations is modes of describing consciousness complementing each other;

2. Development of an integrated approach that involves some kind of universal setting, which is a methodological invariant of constructing different approaches and concepts; Also, a language is needed that will correspond to the tasks of a comprehensive study;

3. Inclusion of interdisciplinary research in the interests of philosophy. But any of the alternatives assumes that there is some common (metaphysical, theoretical, methodological) basis for its implementation.

As soon as we raise questions about the effectiveness, adequacy of attitudes and approaches, methodological difficulties, we are faced with the problem of reflection. The main philosophical method of awareness of consciousness is multilevel reflection. [1; 3-18] However, the problem exists in the fact that reflection as a process of studying consciousness is both its property and the level of consciousness. At the same time, the choice of the method of reflection is influenced by its irreflexive (ordinary) consciousness, which is a priori of the researcher. There is a paradoxical situation: on the one hand, in everyday representations one sees one of the reasons for the multitude of philosophical interpretations of consciousness; on the other hand, they are presented as an implicit basis for solving the problem of consciousness.

The philosophical attitude is the orientation of philosophical reflection, which contains the relation to the object of thought and the preliminary, extremely schematized representation of it. The philosophical attitude is an axiomatic proposition, metaphysical parameters, and ontological postulates that explicitly or implicitly express the essential characteristics of consciousness and set the methodological foundations of interpretation in the comprehension of a particular problem of consciousness.

On the basis of one philosophical attitude, several different approaches can co-exist, read as interpretations of attitudes involved in the development of certain aspects of the problem of consciousness. The methodological basis for solving the problem of consciousness is the search for an adequate philosophical attitude to the approach. In this case, it is necessary to take into account the specific nature of the methodological attitude towards consciousness, on the basis of which a research program is being developed.

Cognitive approach. Under the conditions of the cognitive approach, operations are explored that allow us to identify significant connections within the consciousness, if consciousness is represented as a biological system; also to reveal the connections between the physical states of the human body and mental processes. It is possible that the cognitive method presupposes some preservation of the traditional views of philosophers in describing the nature, structure and evolution of consciousness, which consist in a close connection between the physical state of a person and his mental processes. But in the modern world, the philoso- pher cannot limit his studies on the activity of consciousness to the only conclusion about the existence of dualism - physical and mental, material and ideal, bodily and spiritual. This idea of the identity of the physical and the psychic over time is transformed into a physicalist concept of consciousness, for which a conceptual hypothesis based on the method of reduction, including modeling of the human psyche, is characteristic.

When we trying to connect two different worlds - physical and mental, often arise difficult, which generate skepticism about the existence of consciousness as an independent reality. In the framework of natural science research, R. Penrose compares consciousness with fundamentally noncomputable quantities in mathematics or quantum mechanics. R. Penrose is confident that "nothing in our physical theory of the structure of the universe allows us to explain why some objects have consciousness, while others do not." [5; 37-49] Regardless of R. Penrose's convictions, the quantum theory of consciousness is being developed. This theory suggests that consciousness is closely related to physical processes taking place at the quantum level, and perhaps this path will lead to some results of the study of consciousness in natural-science studies.

Coevolutionary approach. The concept of coevolution appeared in the twentieth century, but the notion of codevelopment of man and nature was still encountered in ancient authors. The historical picture of understanding coevolution comes to the fact that until the New Time the term was not required, because co-development was a natural process for philosophers of the ancient period. In the middle Ages the question of co-development was not raised, since there was an anthropomorphic God who was opposed to nature. In the modern era, the process went in the opposite direction, and the interest in individual elements of the whole gradually increased, classical science began to develop, which in the 19th century began to develop has undergone a collapse. And in the beginning of XX century science has acquired a new one that constructed holism in itself. Against this background, of course, there were problems of coevolution of human nature. The modern coevolutionary approach is aimed at developing the problem of the interaction of consciousness as a Biosystems and the environment. In such a spectrum, consciousness and the environment should be understood as complex systems with coordinated relations, based on changes in the parameters of interaction between the Biosystems and the external environment.

In the natural and humanities within the framework of coevolutionism, questions remain about ethical aspects of the process of scientific experiment, the specifics of bioethics. The blurring of boundaries between the humanities and the natural sciences is palpable when it comes to the empirical nature of research. How will the results of research affect the life of the person as a whole: will they harm, or will they benefit? One can only assume that for understanding objective truth, there is not enough knowledge and methods of another sphere. Science originated in a synthetic form and it again needs to move into this state.

Dynamic approach. This approach is based on the idea that consciousness and the unconscious are necessary and interrelated components of the human cognitive system. The individual cognitive system is represented here as a dynamic, hierarchically complex and highly organized whole, whose state is determined by the relations of the conscious and the unconscious. In the process of evolution, new forms of the 
relationship of these fundamental subsystems arise, there is a tendency to expand consciousness and strengthen its management functions in relation to the unconscious.

Most of the natural science studies of consciousness and the unconscious are interdependent with research in the field of neuroscience. Since it is in the structure and functions of the human brain that the main evolutionary acquisitions of a person are fixed. You can identify a set of traditional problems that are considered in connection with the study of subjective reality: 1) the problem of localization of mental functions of consciousness and the unconscious in the human brain; 2) the problem of the cause-effect relationship between the activity of consciousness and the activity of the brain. To these traditional problems, it is quite possible to include the problem of the multiplicity of the substrata of consciousness, it seems, it could arise precisely in connection with the studies of artificial intelligence. But the philosophical and even mythological prehistory of the problem already posed the question: Does the soul (the psyche) have only a person or nature in general, animals, plants, artifacts and other various "substrates" and "substances"?

Before posing the question: What results can scientific research of consciousness and the unconscious give for the development of philosophical ideas about the subject of cognition and the dynamics of consciousness and the unconscious in the structure of the subject of cognition? It must be pointed out that such a question should be preceded by the systematization of the basic conceptual and methodological approaches to the study of consciousness and subjective reality in the natural sciences within which empirical data were obtained.

Conclusion. With the increasing interest of modern man to the problem of consciousness, there is a competitive struggle among scientists, which multiplies approaches to solving the problem of consciousness. So next to the actual philosophical decisions in the philosophy of consciousness, specific scientific and interdisciplinary interpretations are involved. Through this synthesis, the analysis of scientific results in the sphere of cognition of consciousness stimulates the rapid reaction of philosophy to scientific innovation. For example, thanks to cognitive sciences, it is possible to exper- imentally test some philosophical ideas regarding the solution of the problem of consciousness. In addition, the results of experimental studies of cognitive structures and mechanisms within the framework of neuroscience create a basis for empirical substantiation of a number of theoretical positions in philosophy. To describe the mechanisms of the work of consciousness in philosophy, natural science methodologies and models are increasingly being used. These are models of artificial intelligence, synergetic models (the model of dynamic chaos, the model of the process of selforganization), the classical model of physics (for describing everyday consciousness), the quantum model (for solving the problems of the relationship between consciousness and the unconscious, modeling of mental processes). However, there remains a problem of methodological properties concerning the use of natural-science research methods and generalizations based on them in the philosophical explanation of the phenomenon of consciousness. At the present stage of the development of science, the process of dialogue between researchers of consciousness and cognition may have entered a phase of reviewing the dialogue interpretation and coherence of meaning contained in the concept of consciousness of different directions of the philosophy of consciousness, with the meaning of the context created together. This dialogue is so dynamic that it seems almost impossible to trace all aspects of its development. Perhaps, it is worth paying special attention to the methodological invariants of constructing the context of consciousness. Such an approach would allow us to put forward hypothetical theories about the future possible meanings of such an element of this dialogue as consciousness.

Prospects of the philosophical analysis of the results of the study of consciousness, its origin, formation and development are based on conceptual models, relying on concrete scientific material. It rather speaks not so much of the hypothetical possibility of constructing a single unified theory of consciousness (the "science of consciousness"), but rather the direct development of the philosophy of consciousness, which does not reject the value of natural scientific results, preserving the status of philosophical thinking and understanding its meaning for solving the problem of consciousness.

\section{ЛИТЕРАТУРА}

1. Кузнецов В.Ю. Сдвиг от классики к неклассике и наращивание порядков рефлексии в философии // Вестник Московского университета. 7(1), 2008. С. 3-18.

2. Меркулов И. П. Когнитивная модель сознания // Эволюция. Мышление. Сознание. М: Канон+, 2004. С. 36.

3. Шульга Е.Н. Философии сознания: концепции, подходы и теория интерпретации // Философия сознания: классика и современность. М: Издатель Савин С.А., 2007. С. 268-274.

4. Feyerabend P. Realism. Rationalism and Scientific Method. Cambridge: Philosophical Papers. Vol. 3, 1999. C. 83.

5. Penrose R., Gardner M. The Emperor's New Mind: Concerning Computers, Minds, and the Laws of Physics (Popular Science). USA: Oxford University Press, 2002. C. 37-49.

\section{REFERENCES}

1. Kuznecov V. Ju. The shift from the classical to the nonclassic and the building up of the order of reflection in philosophy. M: Bulletin of Moscow University. No. 7(1), 2008. p. 3-18.

2. Merkulov I. P. Cognitive model of consciousness // Evolution. Thinking. Consciousness. M: Kanon+, 2004. p. 36.

3. Shul'ga E.N. Philosophy of Consciousness: Concepts, Approaches and Theory of Interpretation // Philosophy of Consciousness:

Classics and Modernity. M: Publisher Savin S.A., 2007, p. 268274.

4. Feyerabend P. Realism. Rationalism and Scientific Method. Cambridge: Philosophical Papers. Vol. 3. 1999, p. 83.

5. Penrose R., Gardner M. The Emperor's New Mind: Concerning Computers, Minds, and the Laws of Physics (Popular Science). USA: Oxford University Press. 2002, p. 37-49.

\section{Методологическая сложность в изучении сознания}

\section{К. И. Зобенко}

Аннотация. Почему мы сознаем? Как может быть, что информация, обрабатываемая в мозге человека, сопровождается субъективным опытом? Неотъемлемой частью проблемы сознания является методология его решения. Автор рассматривает различные методы исследования сознания как сближение основных свойств сознания в связи с изменением методологических характеристик исследовательских программ. Методологический плюрализм, характерный для современной философии сознания, проявляется, прежде всего, как набор исследовательских стратегий для решения проблемы сознания и их интерпретаций.

Ключевье слова: сознание, методология, плюрализм, философская установка, рефлексия, подходьл. 